\title{
Healthcare Professional's Knowledge about Cost Related Medication Information in Saudi Arabia
}

\author{
Yousef Ahmed Alomi ${ }^{1, *}$, Dima Ahmad Alaskari², Malak Mohammad Almelfi², Dima Ali Badawi ${ }^{3}$, \\ Abdullah Mohammad Alshihri ${ }^{4}$ \\ ${ }^{1}$ The Past General Manager of General Administration of Pharmaceutical Care and \\ The Past Head, National Clinical pharmacy and pharmacy practice and Pharmacy R and D Administration, Ministry of Health, \\ Riyadh, KSA . \\ ${ }^{2}$ General Administration of Pharmaceutical Care, Ministry of Health, Riyadh, SAUDI ARABIA. \\ ${ }^{3}$ Pharmaceutical Care Services, Saudi Germany Hospital, Aseer, SAUDI ARABIA. \\ ${ }^{4}$ Head, Pharmaceutical Care Services, Abha Maternity and Children Hospital, Abha, SAUDI ARABIA.
}

\section{Received: 02 June 2018; \\ Accepted: 28 August 2018 \\ *Correspondence to: \\ Dr. Yousef Ahmed Alomi,}

The Past General Manager of General Administration of Pharmaceutical Care, The Past Head, National Clinical pharmacy and pharmacy practice, Head, Pharmacy $R$ and $D$ Administration, Ministry of Health, P.O.BOX 100, Riyadh 11392, Riyadh, SAUDI ARABIA. Email:yalomi@gmail.com

Copyright: (c) the author(s),publisher and licensee Indian Academy of Pharmacists. This is an open-access article distributed under the terms of the Creative Commons Attribution Non-Commercial License, which permits unrestricted non-commercial use, distribution, and reproduction in any medium, provided the original work is properly cited.

\begin{abstract}
Purpose: To explore the Healthcare Professionals and Knowledge of Medications cost in Saudi Arabia. Methods: It is a 4-months cross-sectional survey of healthcare professionals and knowledge of medicines. The survey consisted of two-part, demographic information and second part forty-nine questions divided into four domains. It included domain one: Primary or essential information about healthcare providers medication, domain two: healthcare professionals information about the drug-related problem, domain three: healthcare professionals information about drug-related cost and domain four: Healthcare providers perception of medications. All type of healthcare professionals included in the study. Medline Plus health information and DailyMed-INH elements information from National Institute of Health United State of America were used. The 5-point Likert response scale system was used. The questions were open and closed-ended. The survey was distributed through social media by using what's App to more than one thousand healthcare professionals overall Kingdom of Saudi Arabia. The survey was made in an electronic format and it analyzed domain three: healthcare professional's information about drug-related cost through survey monkey system. Results: The total responders were (188) Healthcare professionals. Of those 177 (95.16\%) were Saudi and 9 (4.84\%) were non-Saudi. The gender distribution 120 (63.83\%) were females and $68(36.17 \%)$ were males. The most of Healthcare professionals were pharmacist 93 (71.54\%), followed by nurses $18(13.85 \%)$ and physicians 15 (11.54\%). The most type of medications used was anti-hypertension medicines, anti-diabetic medicines, Skin medications and drugs for Respiratory Diseases. Also, the most number of medications taken either one 29 (15.85\%) or two 17 (9.29\%). The healthcare professionals showed good knowledge with both complete and incomplete information about drug storage at room temperature $148(81.3 \%)$ or refrigerator $143(77.7 \%)$, protect medication from light exposures $133(72.3 \%)$ and how to behave with an expired medication 127 (70.5\%). The healthcare professionals had not adequate information with both complete and incomplete information about prescription prices 110 (59.78\%) and imperfect knowledge about Health insurance coverage of medications 69 (37.9\%). The healthcare professional's knowledge about missing of medications, led patient visit doctor clinic $35(18.72 \%)$, visit the pharmacy $50(27.47 \%)$, visit hospital emergency 17 (9.24\%) hospital admission 20 (10.87\%) or intensive care admission 8 (4.79\%). Conclusion: Healthcare professional missed medication-related cost knowledge. Healthcare professionals may implicate in drug-related problems with burden cost. Healthcare providers demanded of Drug-related prices and drug cost awareness program in Saudi Arabia.
\end{abstract}

Keyword: Healthcare professional, Knowledge, Cost, Medications, Ministry of Health, Saudi Arabia.

\section{INTRODUCTION}

The East patient visited or admitted to hospital had a different particular therapy plan. The plan consisted of a process of non-drug therapy and drug therapy. Starting from patient assessment with diagnosis, laboratory investigation and drug therapy with related supportive management. All the process had a total cost and individual cost for each step including medications cost. ${ }^{[1]}$ The medication costs considerations is a significant part of the treatment plan. The high costs of the drugs may prevent the patient from treatment or continue treatment and avoid going to the hospital or take medical advice. The lack of vital importance of treatment costs may increase the incidence of diseases very significantly, especially in developing countries or low economic layer. Accordingly, the healthcare professionals must strive to provide proper care at the appropriate cost that helps the patient and provides him with comfort and acceptance about his medications used. This analysis supports the extent to which professional health care is aware of the costs of the drug and the importance of this in the treatment plan. The 
systemic review and other studies showed that most physicians are not aware of drug therapy cost. ${ }^{[2-4]}$ Another study discussed the cost of medications related to pharmacists and nurses. ${ }^{[5-6]}$ It seldom to find investigation consisted of healthcare professionals with the cost of medication knowledge in worldwide or Saudi Arabia and Gulf or Middle East counties. The objective of the study was to explore the healthcare professional's knowledge about the cost of medications in Kingdom of Saudi Arabia.

\section{METHODS}

It is a 4-months cross-sectional survey of healthcare professionals and knowledge of medicines. The survey consisted of two-part, demographic information and second part forty-nine questions divided into four domains. ${ }^{[7]}$ It included domain one: Primary or essential information about healthcare providers medication, domain two: healthcare professionals information about the drug-related problem, domain three: healthcare professionals information about drug-related cost and domain four: Healthcare providers perception of medications. ${ }^{[8]}$ All type of healthcare professionals included in the study. ${ }^{\left[{ }^{[9]}\right.}$ Medline Plus health information and DailyMed-INH elements information from National Institute of Health United State of America were used. ${ }^{[10-11]}$ The 5 -point Likert response scale system was used. The questions were open and closed-ended. The survey was distributed through social media by using what's App to more than one thousand healthcare professionals overall Kingdom of Saudi Arabia. A message reminder was sent to healthcare professionals after two weeks and additional message reminder was sent to healthcare professionals after four weeks. The survey was made in an electronic format and it analyzed domain three: healthcare professional's information about drug-related cost through survey monkey system.

\section{RESULTS}

The total responders were (188) Healthcare professionals. Of those 177 $(95.16 \%)$ were Saudi and $9(4.84 \%)$ were non-Saudi. The gender distribution $120(63.83 \%)$ were females and $68(36.17 \%)$ were males. The majority of them in age (18-44) 86.7\% and located at Asir region $89(47.34 \%)$ and Riyadh region $46(24.5 \%)$. The most of Healthcare professionals were pharmacist 93 (71.54\%), followed by nurses 18 (13.85\%) and physicians 15 (11.54\%). The most responders had the Bachelor Degree 126 (67.02\%) followed by Diploma $33(17.55 \%)$ and Master degree $22(11.70 \%)$ The most type of medications used was anti-hypertension medicines, antidiabetic medicines, Skin medications and drugs for Respiratory Diseases. Also, the most number of medication taken either one 29 (15.85\%) or two $17(9.29 \%)$ as explored in Table 1 . The healthcare professionals showed good knowledge with both complete and incomplete information about drug storage at room temperature $148(81.3 \%)$ or refrigerator $143(77.7 \%)$, protect medication from light exposures $133(72.3 \%)$ and how to behave with an expired medication 127 (70.5\%). The healthcare professionals had not adequate information with both complete and incomplete information about prescription prices $110(59.78 \%)$ and imperfect knowledge about Health insurance coverage of medications $69(37.9 \%)$ as explored in Table 2. The healthcare professional's knowledge about missing of medications, led patient visit doctor clinic 35 (18.72\%), visit the pharmacy $50(27.47 \%)$, visit hospital emergency 17 (9.24\%) hospital admission 20 (10.87\%) or intensive care admission 8 (4.79\%). as explored in Table 3.

\section{DISCUSSION}

The pharmacy strategic plan started with several pharmacy practices and clinical pharmacy programs..$^{[12-13]}$ There were programs focused on costrelated issues, for instance, Pharmacoeconomics programs, a cost avoidance of prevention medication errors, a cost avoidance of drug information centers, a cost avoidance of pharmacist intervention and cost additionally

\begin{tabular}{|c|c|c|}
\hline Characteristics & Response N & Response \% \\
\hline \multicolumn{3}{|l|}{ Sex } \\
\hline Female & 120 & $63.83 \%$ \\
\hline Male & 68 & $36.17 \%$ \\
\hline \multicolumn{3}{|l|}{ Nationality } \\
\hline Saudi & 177 & $95.16 \%$ \\
\hline Non-Saudi & 9 & $4.84 \%$ \\
\hline \multicolumn{3}{|c|}{ Answered question: 186 and Skipped question: 2} \\
\hline \multicolumn{3}{|l|}{ Age } \\
\hline$<18$ & 5 & $2.66 \%$ \\
\hline $18-29$ & 112 & $59.57 \%$ \\
\hline $30-44$ & 51 & $27.13 \%$ \\
\hline $45-59$ & 19 & $10.11 \%$ \\
\hline $60+$ & 1 & $0.53 \%$ \\
\hline \multicolumn{3}{|l|}{ Healthcare professional } \\
\hline Doctor & 15 & $11.54 \%$ \\
\hline Dentist & 4 & $3.08 \%$ \\
\hline Pharmacist & 93 & $71.54 \%$ \\
\hline Nurse & 18 & $13.85 \%$ \\
\hline Others & 33 & $25.38 \%$ \\
\hline \multicolumn{3}{|c|}{ Answered question:130 and skipped questions: 58} \\
\hline \multicolumn{3}{|l|}{ Total Experiences } \\
\hline Doctorate degree & 7 & $3.72 \%$ \\
\hline Master degree & 22 & $11.70 \%$ \\
\hline Bachelor Degree & 126 & $67.02 \%$ \\
\hline Diploma & 33 & $17.55 \%$ \\
\hline High school & 7 & $3.72 \%$ \\
\hline Intermediate School & 0 & $0.00 \%$ \\
\hline Primary School & 0 & $0.00 \%$ \\
\hline Not educated & 0 & $0.00 \%$ \\
\hline \multicolumn{3}{|l|}{ The current medications } \\
\hline Diabetic Medication & 26 & $13.83 \%$ \\
\hline Antihypertensive Medication & 28 & $14.89 \%$ \\
\hline Cardiac Medication & 7 & $3.72 \%$ \\
\hline Asthma Medication & 16 & $8.51 \%$ \\
\hline Derma Medication & 18 & $9.57 \%$ \\
\hline Anti-Rheumatic & 13 & $6.91 \%$ \\
\hline Do not take anything now & 125 & $66.49 \%$ \\
\hline Others & 27 & $14.36 \%$ \\
\hline \multicolumn{3}{|c|}{ Number of current medication taken } \\
\hline Nothing & 121 & $66.12 \%$ \\
\hline 1 & 29 & $15.85 \%$ \\
\hline 2 & 17 & $9.29 \%$ \\
\hline 3 & 7 & $3.83 \%$ \\
\hline 4 & 2 & $1.09 \%$ \\
\hline 5 & 2 & $1.09 \%$ \\
\hline 6 & 2 & $1.09 \%$ \\
\hline 7 & 3 & $1.64 \%$ \\
\hline 8 & 0 & $0.00 \%$ \\
\hline 9 & 0 & $0.00 \%$ \\
\hline 10 & 0 & $0.00 \%$ \\
\hline more than 10 & 0 & $0.00 \%$ \\
\hline
\end{tabular}


Table 2: The Healthcare professional's knowledge of Medication storage information.

\begin{tabular}{|c|c|c|c|c|c|c|c|c|}
\hline No. & Answer Options & $\begin{array}{l}\text { Complete } \\
\text { information }\end{array}$ & $\begin{array}{l}\text { Incomplete } \\
\text { information }\end{array}$ & $\begin{array}{l}\text { Weak } \\
\text { information }\end{array}$ & $\begin{array}{l}\text { do not } \\
\text { have this } \\
\text { information }\end{array}$ & $\begin{array}{l}\text { Does not } \\
\text { need this } \\
\text { information }\end{array}$ & $\begin{array}{l}\text { Rating } \\
\text { Average }\end{array}$ & Response N \\
\hline 1 & Storage of medication at room temperature & 110 & 38 & 16 & 9 & 9 & 4.27 & 182 \\
\hline 2 & Storage of medication in Refrigerator & 104 & 39 & 13 & 16 & 12 & 4.13 & 184 \\
\hline 3 & Protect medication from light exposures & 95 & 38 & 17 & 23 & 11 & 3.99 & 184 \\
\hline 4 & How to deal with expired medications & 98 & 29 & 12 & 27 & 14 & 3.94 & 180 \\
\hline \multicolumn{9}{|c|}{ Healthcare professionals Knowledge of Medication prices information } \\
\hline No. & Answer Options & $\begin{array}{l}\text { Complete } \\
\text { information }\end{array}$ & $\begin{array}{l}\text { Incomplete } \\
\text { information }\end{array}$ & $\begin{array}{l}\text { Weak } \\
\text { information }\end{array}$ & $\begin{array}{l}\text { do not } \\
\text { have this } \\
\text { information }\end{array}$ & $\begin{array}{l}\text { does not } \\
\text { need this } \\
\text { information }\end{array}$ & $\begin{array}{l}\text { Rating } \\
\text { Average }\end{array}$ & $\begin{array}{l}\text { Response } \\
\text { Count }\end{array}$ \\
\hline 1 & General medication prices & 49 & 61 & 38 & 21 & 15 & 3.59 & 184 \\
\hline 2 & Health insurance coverage of medications & 36 & 33 & 29 & 47 & 37 & 2.91 & 182 \\
\hline
\end{tabular}

\begin{tabular}{|l|l|l|l|l|l|}
\hline \multicolumn{2}{|l}{ Table 3: The patient's outcome of drug-related problems. } \\
\hline Answer Options & Yes & Response \% & No & Response \% & Total Response N \\
\hline Ambulatory clinic visit & 35 & $18.72 \%$ & 152 & $81.28 \%$ & 187 \\
\hline Pharmacy visit & 50 & $27.47 \%$ & 132 & $72.53 \%$ & 182 \\
\hline Emergency visit & 17 & $9.24 \%$ & 167 & $90.76 \%$ & 184 \\
\hline Hospital admission & 20 & $10.87 \%$ & 164 & $89.13 \%$ & 184 \\
\hline Critical Care admission & 8 & $4.79 \%$ & 159 & $95.21 \%$ & 167 \\
\hline Answered question: 188 and skipped question:0 & & & \\
\hline
\end{tabular}

avoidable of pharmacist running total parental nutrition. ${ }^{[14-16]}$ Another program established for the cost of medications awareness for healthcare professionals, for instance, national drug information center through Ministry of Health hotline call Center 937, MOH corporate pharmacy and therapeutics committee and $\mathrm{MOH}$ formulary management. ${ }^{[17]}$ Also, the measurements of actual knowledge of medications cost done through this investigation. The finding of the study showed two third of healthcare professionals had adequate medications knowledge of cost-related issues including how to store the medications, medication protection from light and how to deal with expired medications. This is excepted because they are healthcare professionals and they should know all those elements during college education. Still, one of them missed that information and had a risk with distribution of information to the patients. The healthcare professionals had imperfect knowledge of medications prices or health care insurance coverage because all healthcare services provided to the Saudi patient as free of charge. Also, the diagnostic related group implemented in Saudi Arabia. The results resemble what reported by Cogdill, B et al. and by Allan, MG et al. and better than what reported by Reichert, S et al. with physicians and better than what reported by Emily-Jane $\mathrm{W}$ et al. with the pharmacists. ${ }^{[-4,18]}$ The finding of the study showed that there are discrepancies in the information among health practitioners about the knowledge of drug costs, but they still need more to spread the culture of the medical economy and have a significant impact on health, economy and the need to cover health insurance for the treatment of patients. The Information about drug storage and drug protection is satisfactory to many. Social characteristics of the patient and the cost of medication can determine the relationship between the patient and the health provider and thus influence equity of health issue. When drug therapy was chosen, cost of medication becomes an important determinant as to whether patients will buy the prescribed drugs or not. ${ }^{[19]}$ The missing of medications knowledge may lead the healthcare professionals to visit the pharmacy or ambulatory care clinic. The visiting is not clear before or after misusage of medications. Some healthcare professionals, unfortunately, may misuse of medications due absent knowledge of medications lead to hospitals admission or visit emergency development or critical care admission. Those sequences raised the economic burden in the healthcare system with straightforward information with from unexpected populations. It is hard to find study discussed healthcare worker admitted to the hospital or emergency visits due to medications use to compare with our results. If our subject considered as patients, the comparisons showed the result of ambulatory care visit is high than what reported by Hammerman, H. et al. That has related straightforward access to the healthcare professional visit clinic without any charges. Also, the lower prices of privates ambulatory care clinics. ${ }^{[20]}$ The results of hospital admission resemble what reported by Nivya, $\mathrm{K}$ et al. While the results of emergency visit resemble what reported by Al-Arifi, $\mathrm{M}$ et al. almost what reported by Alghamdy, MS et al. and Rashed A.N. et al. ${ }^{[21-24]}$ The results of drug-related problems caused critical admission almost resemble what reported by Abdelaziz, $\mathrm{K}$ et al. and Hammerman, H. et al. ${ }^{[20,25]}$ Most of the healthcare provider's perspective results resemble what reported within entire patients and has concluded that there is no difference in the attitude or economic burden on health care system between healthcare workers and regular patients. To minimize the possibility drug-related complications, when the healthcare professionals had several medications the medications used should also be minimized. ${ }^{[26]}$ Especially in Older participants more likely susceptible to side effects, many sensitive to medications and they had pre-existing conditions that may increase both the qunatities and qualities of adverse effects. ${ }^{[27]}$

\section{CONCLUSION}

The healthcare Professionals lacks much information related to the cost of medicine, its effect on treatment and any damages that lead to increased 
costs and losses in health care as well as drug problems. They still need more education and information about the cost of the medicine and the resulting burden and importance the health care provider's request for the drug awareness program and the cost of medicines program in Saudi Arabia.

\section{ACKNOWLEDGMENT}

None

\section{CONFLICT OF INTEREST}

None

\section{ABBREVIATIONS}

KSA: Kingdom of Saudi Arabia; MOH: Ministry of Health; CBAHI: Saudi Center for Accreditation of Healthcare Institutions.

\section{REFERENCES}

1. Ernst FR, Grizzle AJ. Drug-related morbidity and mortality: Updating the costof-illness model. J Am Pharm Assoc. 2001;41(2):192-9.

2. Allan GM, Lexchin J, Wiebe N. Physician awareness of drug cost: A systematic review. PLoS Med. 2007;4(9):1486-96.

3. Reichert S, Simon T, Halm EA. Physicians' Attitudes About Prescribing and Knowledge of the Costs of Common Medications. Arch Intern Med. 2000;160(18):2799-803.

4. Cogdill B, Nappi JM. Assessment of Prescribers' Knowledge of the Cost of Medications. Ann Pharmacother. 2012;46(2):200-7.

5. Shinde S. Pharmacist Perspectives on Medication Costs and Affordability: A Pilot Study. Inov Pharm. 2014;5(2).

6. Mendelson D, Ramchand R, Abramson R, Tumlinson A. Prescription drugs in nursing homes: managing costs and quality in a complex environment. NHPF issue Br Natl Heal Policy Forum Georg Washington Univ. 2002;(784):1-18.

7. Salhia HO, Ali A, Rezk NL, Metwally AE. Perception and attitude of physicians toward local generic medicines in Saudi Arabia: A questionnaire-based study. Saudi Pharm J. 2015;23(4):397-404.

8. Lindsay BR, Olufade T, Bauer J, Babrowicz J, Hahn R. Patient-reported barriers to osteoporosis therapy. Arch Osteoporos. 2016;11(1):3-10.

9. Franks TJ, Burton DL, Simpson MD. Patient medication knowledge and adherence to asthma pharmacotherapy: a pilot study in rural Australia. Ther Clin Risk Manag. 2005;1(1):33-8.

10. MedlinePlus - Health Information from the National Library of Medicine. Available from: https://medlineplus.gov/

11. DailyMed [Internet]. Available from: https://dailymed.nlm.nih.gov/dailymed/

12. Alomi YA. National Pharmacy Practice Programs at Ministry of Health in Saudi Arabia. JPharm Pharm Scien. 2015;1(2):17-8.

13. Alomi YA. National Pharmacy Administration Programs at Ministry of Health in
Saudi Arabia. BAOJ Pharm Sci. 2015;1(9)

14. Alomi YA, Alanazi AA, Alsallouk SA, Almaznai MM, Abu-Alnaja NI, Alduhilan M, et al. Cost-Efficiency Of Medication Safety Program At Pediatrics, Obstetrics and Gynecology Hospital, East Province, Saudi Arabia. Value Heal. 2016;19(7):A464.

15. Alomi YA, Fallatah AO. Economics outcomes of pharmacist managed neonatal total parenteral nutrition services at ministery of health in saudi arabia. In: Value in Health. 2017;20:a42-a42.

16. Alomi YA, Fallatah AO. Cost Avoidance Of Pharmacist Running Pediatrics Total Parenteral Nutrition Services At Ministry Of Health In Saudi Arabia. Value Heal. 2016;19(7):A461.

17. Alomi YA, Almudaiheem HY, Alarnous T, Alshurei S, Alsharafa A, Alzahrani T, et al. Cost-efficiency of national drug information center through the ministry of health hotline calling services (937) in Saudi Arabia: Application of American model. Value Heal. 2015;18(7):A735.

18. Emily-Jane Willmot, Beverley A Lawton, Sally B Rose SB. Exploring knowledge of prescription charges: a cross-sectional survey of pharmacists and the community. J New Zeal Med Assoc. 2009;21(122):19-24.

19. Ssemaluulu R, Adome R. Patients' knowledge of medication use as an equity issue in health care : Do health workers pay attention to this?. 2006. Available from: http://www.equinetafrica.org/sites/default/files/uploads/documents/ CBP3EHSadome.pdf

20. Hammerman $\mathrm{H}$, Kapeliovich $\mathrm{M}$. Drug-related cardiac iatrogenic illness as the cause for admission to the intensive cardiac care unit. Isr Med Assoc J. 2000;2(8):577-9.

21. Nivya K, Kiran VSS, Ragoo N, Jayaprakash B, Sonal SM. Systemic review on drug-related hospital admissions - A PubMed based search. Saudi Pharm J. 2015;23(1):1-8.

22. Al-Arifi M, Abu-Hashem H, Al-Meziny M, Said R, Aljadhey H. Emergency department visits and admissions due to drug-related problems at Riyadh military hospital (RMH), Saudi Arabia. Saudi Pharm J. 2014;22(1):17-25.

23. Alghamdy MS, Randhawa MA, Al-Wahhas MH, Al-Jumaan MA. Admissions for drug-related problems at the Emergency Department of a University Hospital in the Kingdom of Saudi Arabia. J Family Community Med. 2015;22(1):44-8.

24. Rashed AN, Neubert A, Alhamdan H, Tomlin S, Alazmi A, Alshaikh A, et al. Drug-related problems found in children attending an emergency department. Int J Clin Pharm. 2013;35(3):327-31.

25. Abdelaziz K, Abdelrahim ME. Identification and categorisation of drug-related problems on admission to an adult intensive care unit. Eur J Hosp Pharm. 2015;22(3).

26. García DP, Mateus SH. Measurement of patients 'knowledge of their medication in community pharmacies in Portugal. Cien Saude Colet. 2015;20(1):219-28.

27. MacLennan PA, Owsley C, Rue LW, McGwin G. Older Adults ' Knowledge About Medications That Can Impact Driving. AAA Found Traffic Saf. 2009;1-57.

Cite this article as: Alomi YA, Alaskari DA, Almelfi MM, Badawi DA, Alshihri AM. Healthcare Professional's Knowledge about Cost Related Medication Information in Saudi Arabia. J Pharm Pract Community Med. 2018;4(3):163-6. 